\title{
An Empirical Study on the Adult Learning in Cognition and Needs with the Health Community for the Aged Population in Taiwan
}

\author{
Hsiu-Ling Cheng \\ Department of Adult and Continuing Education, National \\ Chung Cheng University, Taiwan \\ E-mail: hsiuling5833@yahoo.com.tw
}

Yu-Ze Shih

Department of Adult and Continuing Education, National

Chung Cheng University, Taiwan

E-mail: astsyz@ccu.edu.tw

\author{
Hui-Chuan Wei \\ Department of Adult and Continuing Education, National \\ Chung Cheng University, Taiwan \\ E-mail: aduhcw@ccu.edu.tw \\ Wei-Min Huang* \\ Department of Healthcare Information Management, \\ National Chung Cheng University, Taiwan \\ E-mail: wmhuang@ mis.ccu.edu.tw
}

\begin{abstract}
The main purpose of this study is to explore the cognition of importance and needs assessment with health community for the aged population. The study adopted a questionnaire survey method and 500 questionnaires from the elderly in Chia-Yi City responded. The statistical analysis of this study indicated significantly that both the cognition and needs were related to the education and health status of the elderly. The open-end questionnaires also showed the "health" theme is a critical variable and lifelong learning is worthy of much more attention.
\end{abstract}

Keywords-Adult Learning; Aged population; Health Community; Cognition of importance; Needs Assessment

\section{INTRODUCTION}

The growing ageing population of Taiwan's is worrisome, and many studies indicate that the most important problem for the elderly in the future is "health", followed by "economic sources" and "care problems" in the case of illness [1].

It is clear that health and the economy are the most significant needs of the elderly at present. In order to meet the advent of the aging society, the future of Taiwan's social welfare policy will have to tilt to the elderly, the proportion of the relevant budget for the elderly will be more and more than before [2].

With the higher elder-dependency ratio, the economic needs and support burden of the elderly population on the working population will increase. Due to the rapid increase of human aging and the extension of life expectancy, traditional social welfare not only faces new challenges, but also shows new opportunities for reform [3].

\section{LITERATURE REVIEW}

\section{A. The problem of population ageing}

Ageing is an important global issue, a complex and multiple-oriented proposition. That is also a social trend that brings opportunities and challenges, which also provide us with a new way of looking for active aging experience. The World Health Organization has developed the conceptual framework of active aging since 2002. The concept is defined as the process of improving the quality of life of the population in the old age and achieving the most appropriate health, social participation and security. It currently has become the international organization recommended the world, the formulation of the elderly health policy of the main reference framework. For health, participation and security as the three basic principles, in addition to emphasizing lifelong learning and the cultivation of personal ability, more emphasis on social participation and community interaction [4].

\section{B. The concept of health community}

The health community is the concept from a healthy city. The purpose of the plan implemented by WHO since 1986 is to integrate health policies and urban policies, promote the physical and mental health of the people and identify with the living environment, whether it is necessary to improve the environment, public health services and community building education, in order to achieve health and places for all by the government and the private sectors. For implementing health promotion, WHO started a series of healthy city plans campaign, hopefully by the implementation of the campaign could improve the city's problems, and through public participation and public-private partnerships together. That can drive this program to enable city dwellers and lead a healthy life. Therefore the urban policy of the period would improve

*Corresponding author email: wmhuang@mis.ccu.edu.tw 
social and environmental development, thus this stage is also known as the new public health phase (the new Health) ( WHO, 1986) [5] [6] [11].

\section{Cognitive theory}

The cognition is a concept that has been paid more and more attention in modern psychology. According to general psychology, cognition is the internal course of individual thinking and problem solving, and it is necessary to understand the relationship between stimulation and stimulation in order to have an epiphany to solve the problem. The cognitive development theory of Piaget's (J. Piaget) sees cognition as the psychological process of understanding or understanding the internal and external environment, and promotes the development of cognition and the development of mental structure by cognitive operation such as adaptation and assimilation. As far as the information processing theory of cognitive psychology is concerned, cognition refers to the psychological process of the individual receiving and using the information, so the cognitive process includes: information input, conversion, storage, retrieval, and application, etc. Cognitive processing patterns can be used to interact from the top down, down, or both [7].

\section{RESEARCH METHODS}

\section{A. The conceptual framework}

This study is based on an analysis of current situation, critical problems, motivations and previous literature. As shown in the figure 1 . The research conceptual framework includes the predictive variable (predictors) and the result variable (outcomes). The predictive variable is the personal background variable, and the outcome variable includes the cognition and demand of the healthy community. The study's predictive variable, including gender, age, education level, work status, marriage, residence and health status, can be learned from the research framework [8-9].

The outcome variables mainly include the cognition and demand situation in the healthy community, and the secondary variables that can be analyzed include living environment, life function, community support and participation, multiple resources, economic conditions, cultural characteristics and health care services. This study combines cognitive and demand-related factors to construct an ideal health Community assessment scheme, forming the conceptual framework of this study, such as the study of the conceptual framework, figure 1.

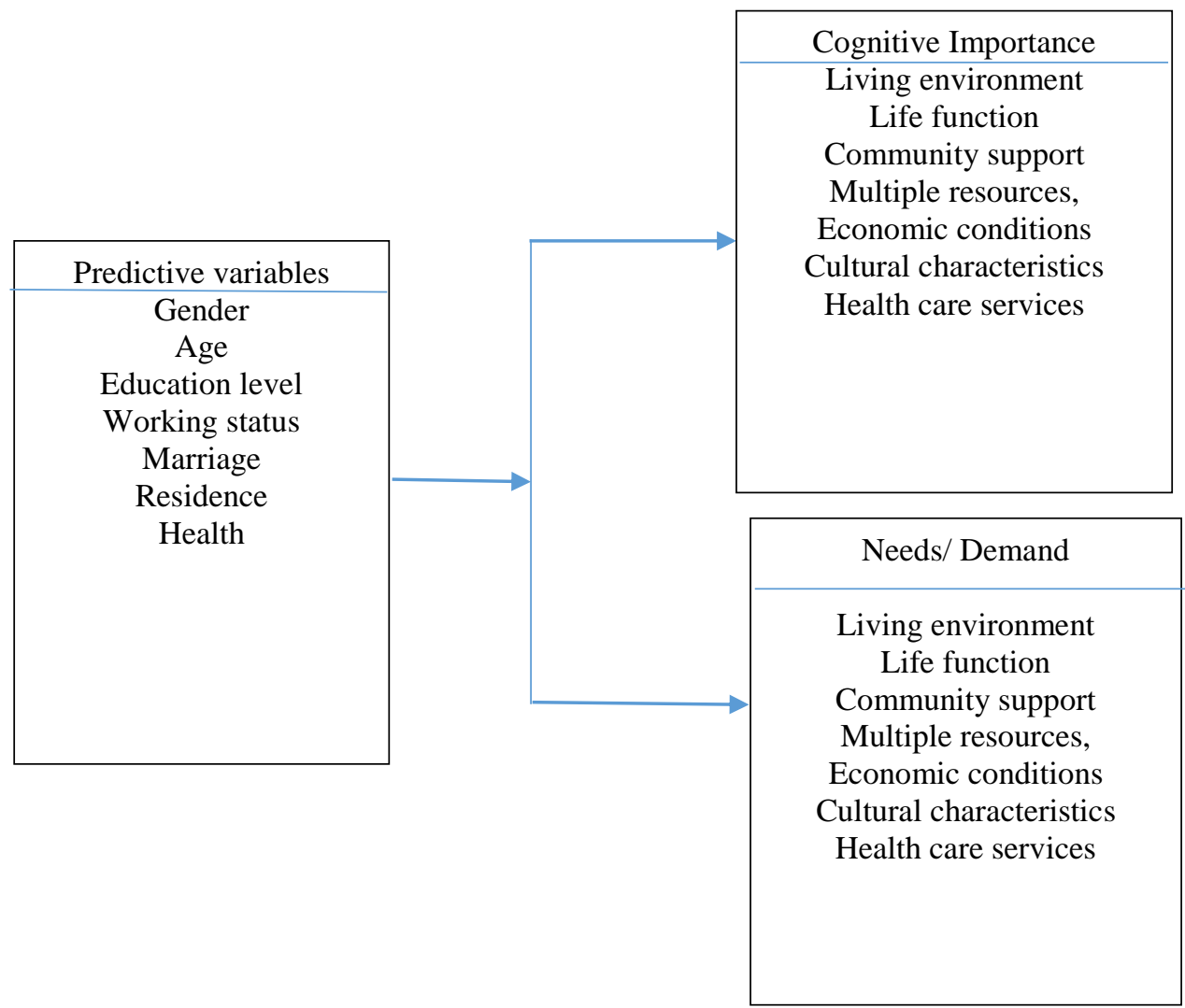

Fig. 1. The conceptual framework

\section{B. Research Hypothesis}

Based on the conceptual framework and research issues, the present research hypothesis is as follows to test:
H1: Elderly people of different personal backgrounds will have differences in the perception of building a healthy community.

H2: There are differences in the needs of healthy communities for people of different personal backgrounds. 
H3: The age of the elderly people is associated with their personal background with regard to the cognitive importance and degree of demand for constructing a healthy community. [10]

\section{Research Design}

This study is mainly to explore the cognition and needs of the elderly people in Chia-Yi City of Taiwan for the construction of healthy community. This study is thus for the elderly people currently living in the city. The total number of matrices is approximately 35,000 of people. Questionnaire administrations are conducted in person and sampled in randomly sampling design. The number of questionnaires issued is 538, sample ratio is approximately $1.5 \%$.

\section{RESULTS}

\section{A. Personal background data analysis}

Total distribution of this study is 538 questionnaires. Elimination of invalid and wrong questionnaires, total response of valid questionnaires is 500, effective response rate is $92.9 \%$. Personal background information in descriptive statistics including seven items such as: gender, age, education level, work status, marital status, residency status and health status were analyzed. It is known that in Table 1 the majority of the subjects in this study were women, about $60 \%$ (63\%), mostly married, about $70 \%(69.2 \%)$, but there are also many widows $(22.6 \%)$.

TABLE I. BASIC DATA ANALYSIS FOR BACKGROUNDS OF RESPONDENTS $(\mathrm{N}=500)$

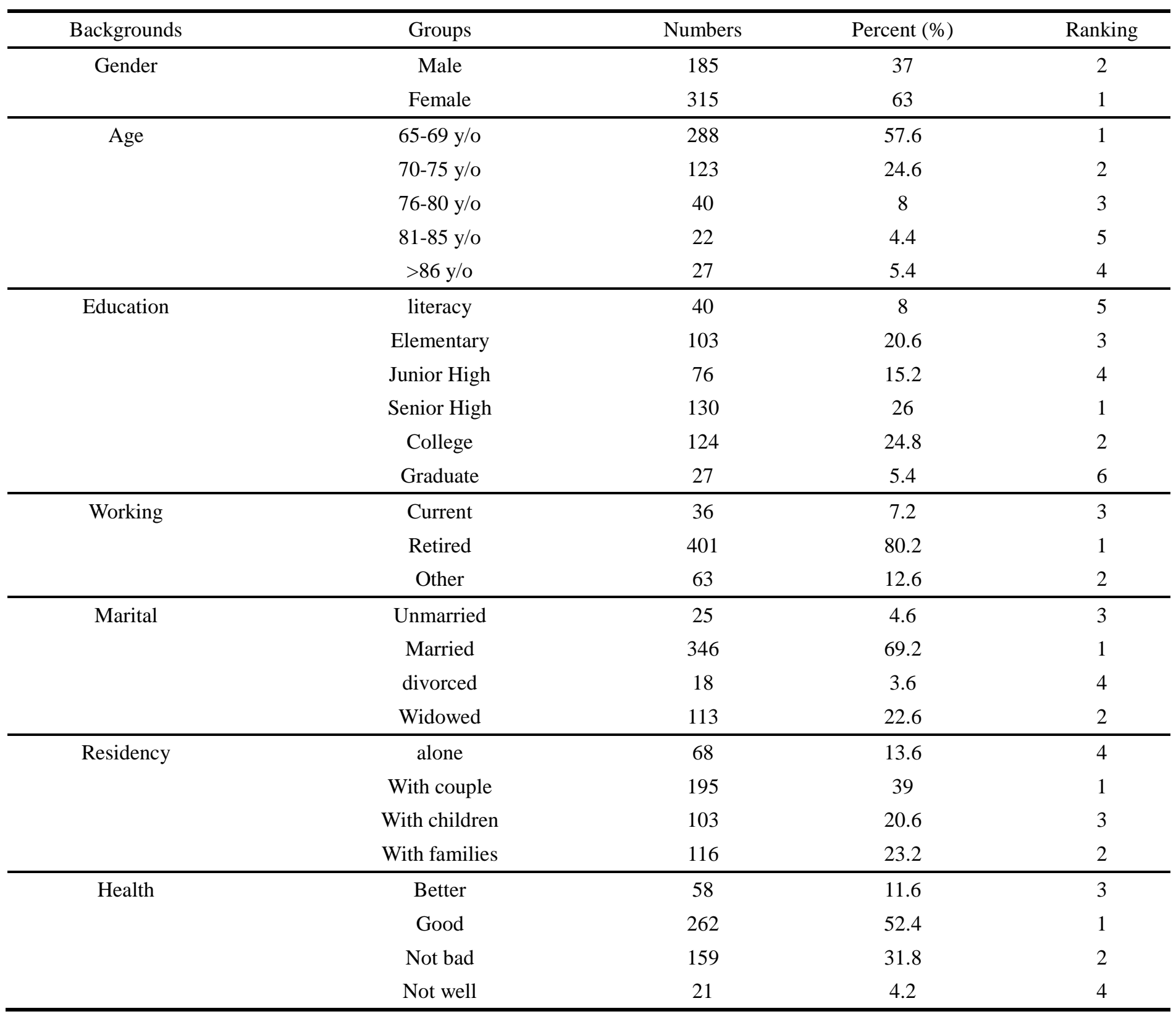


B. An Analysis on the cognition in the importance of elderly people for building a healthy community

It is also indicated that on the table 2 the statistical analysis of the elderly people think most important to construct the "health care service" in the cognitive level of constructing the various dimensions and variables of a healthy community. Secondly, "living environment", "Economic aspects" and "multiple resources" is relatively unimportant. The top 10 of the major variables in each configuration are "community residents can support each other"(4.73), "adequate and sophisticated medical services"(4.68), " The community provides patrol services to ensure personal safety "(4.63)," Adequate preventive health services "(4.61)," Community sanitation clean " (4.59), adequate lighting in the community environment (4.59), multiple health promotion activities (4.56), Plot road leveling (4.56), have enough exercise space (4.56) , "can clearly convey health care information to the elderly" (4.55) The last three ones are "able to support the elderly entrepreneurship" (3.46), providing re-employment opportunities for older people (3.67) and "seniors get paid for work" (3.69), all three belong to the "economic aspects" of the construction surface.

TABLE II. THE COGNITIVE ANALYSIS FOR THE DIMENSION AND VARIABLES IN IMPORTANCE OF ELDERLY PEOPLE FOR CONSTRUCTING A HEALTHY COMMUNITY $(\mathrm{N}=500)$

\begin{tabular}{|c|c|c|c|c|c|c|}
\hline No. & Dimensions & Variables & Average & SD & Ranking & t-test \\
\hline 1 & $\begin{array}{c}\text { Living } \\
\text { Environment }\end{array}$ & Community Sanitation Clean & 4.59 & 0.55 & 5 & 0.000 \\
\hline 3 & $\begin{array}{c}\text { Living } \\
\text { Environment }\end{array}$ & $\begin{array}{l}\text { Adequate lighting } \\
\text { in the Community environment }\end{array}$ & 4.59 & 0.52 & 5 & 0.016 \\
\hline 7 & $\begin{array}{c}\text { Living } \\
\text { Environment }\end{array}$ & $\begin{array}{l}\text { The community provides patrol services to ensure } \\
\text { personal safety }\end{array}$ & 4.63 & 0.57 & 3 & 0.022 \\
\hline 12 & $\begin{array}{l}\text { Community } \\
\text { Support }\end{array}$ & Community residents can support each other & 4.73 & 0.67 & 1 & 0.003 \\
\hline 15 & $\begin{array}{l}\text { Community } \\
\text { Support }\end{array}$ & $\begin{array}{l}\text { Community activities are financially affordable for the } \\
\text { elderly }\end{array}$ & 4.24 & 0.84 & -4 & \\
\hline 16 & $\begin{array}{l}\text { Community } \\
\text { Support }\end{array}$ & $\begin{array}{l}\text { Be able to participate in Community decisions on the } \\
\text { issues of the elderly }\end{array}$ & 4.15 & 0.83 & -5 & \\
\hline 27 & Economic Aspect & To provide a re-employment opportunity for the elderly & 3.67 & 1.01 & -2 & 0.021 \\
\hline 28 & Economic Aspect & Can support the old people to start a business & 3.46 & 1.04 & -1 & 0.004 \\
\hline 29 & Economic Aspect & Elderly people get paid for work & 3.69 & 1.08 & -3 & 0.000 \\
\hline 35 & $\begin{array}{l}\text { Health Care } \\
\text { Services }\end{array}$ & Adequate and comprehensive medical services & 4.68 & 0.53 & 2 & 0.000 \\
\hline 36 & $\begin{array}{l}\text { Health Care } \\
\text { Services }\end{array}$ & Adequate preventive health care services & 4.61 & 0.58 & 4 & 0.002 \\
\hline
\end{tabular}

\footnotetext{
The cognitive average scores for elderly people on the importance of constructing the eight major dimensions for a healthy community were shown in table 4 . As shown in the

order of health care services (4.59), Living Environment (4.54), community support and high participation (4.38), Life function
} (4.34), meeting requirements (4.24), culture, and characteristics (4.23), multivariate Resources (4.19), and Economics (3.79). 


\section{An analysis of the overall level of the needs of elderly} people to construct a healthy community

It is the statistical analysis of the elderly people need "health care services" as the most needed to construct the various dimensions and variables of the healthy community based on the table 3. The second is "living environment", the "Economic aspects" and "multiple resources" of the construction dimensions is relatively unnecessary. The top 10 of the requirements topics in each configuration are "community sanitation clean"(4.57), "adequate lighting in the community environment"(4.56), "Adequate and perfect medical service" (4.55), "Community Road Leveling"(4.49), "community provides patrol services to ensure personal safety"(4.49), adequate preventive health services (4.49), "can clearly convey health care information to the elderly" (4.46), multiple health promotion activities (4.44), have enough exercise space (4.43), "Helping the disadvantaged" (4.39) The last three ones are "able to support the elderly entrepreneurship" (3.31), providing re-employment opportunities for older people (3.45), and "seniors get paid for work" (3.57), all three belong to the "economic aspects" of the construction.

TABLE III. AN ANALYSIS IN THE NEEDS OF THE ELDERLY PEOPLE TO CONSTRUCT THE VARIOUS DIMENSIONS AND VARIABLES FOR THE HEALTHY COMMUNITIES $(\mathrm{N}=500)$

\begin{tabular}{|c|c|c|c|c|c|c|}
\hline No. & Dimensions & Variables & Average & SD & Ranking & t-test \\
\hline 1 & $\begin{array}{c}\text { Living } \\
\text { Environment }\end{array}$ & Community Sanitation Clean & 4.57 & 0.62 & 1 & 0.015 \\
\hline 2 & $\begin{array}{c}\text { Living } \\
\text { Environment }\end{array}$ & District Road Formation & 4.49 & 0.64 & 4 & \\
\hline 3 & $\begin{array}{c}\text { Living } \\
\text { Environment }\end{array}$ & $\begin{array}{c}\text { Adequate lighting } \\
\text { in the Community environment } \\
\end{array}$ & 4.56 & 0.64 & 2 & 0.004 \\
\hline 7 & $\begin{array}{c}\text { Living } \\
\text { Environment }\end{array}$ & $\begin{array}{c}\text { The community provides patrol services to ensure } \\
\text { personal safety }\end{array}$ & 4.49 & 0.69 & 4 & \\
\hline 27 & Economic Aspect & $\begin{array}{l}\text { To provide a re-employment opportunity for the } \\
\text { elderly }\end{array}$ & 3.45 & 1.05 & -2 & 0.000 \\
\hline 28 & Economic Aspect & Can support the old people to start a business & 3.31 & 1.02 & -1 & 0.000 \\
\hline 29 & Economic Aspect & Elderly people get paid for work & 3.57 & 1.10 & -3 & 0.000 \\
\hline 35 & $\begin{array}{l}\text { Health Care } \\
\text { Services }\end{array}$ & Adequate and comprehensive medical services & 4.55 & 0.58 & 3 & 0.000 \\
\hline 36 & $\begin{array}{l}\text { Health Care } \\
\text { Services }\end{array}$ & Adequate preventive health care services & 4.49 & 0.67 & 4 & 0.005 \\
\hline
\end{tabular}

V. AN ANALYSIS OF THE DIFFERENCES BETWEEN THE COGNITION AND NEEDS OF ELDERLY PEOPLE IN DIFFERENT BACKGROUNDS

\section{A. Gender}

In the case of a gender-dependent variable, the older person takes a separate sample for the construction of the cognitive importance of the building of a healthy community. For t-test analysis results showed that in support of the elderly to start a business $(\mathrm{p}<0.001)$, multicultural facilities $(\mathrm{p}<0.001)$, all kinds of lifelong learning courses $(\mathrm{p}<0.001)$, elder friendly restaurant $(\mathrm{p}<0.01)$, community sanitation Clean $(\mathrm{p}<0.05)$, cultural activities with Community characteristics $(\mathrm{p}<0.05)$, and so on, a total of six topics have statistical differences.

\section{B. Age}

Taking the age level as the independent term, the elderly people are dependent on the variables of the cognitive importance of constructing a healthy community, and then the univariate analysis is carried out by a single factor. (One way ANOVA), if significant differences are achieved, then multiple comparisons are performed afterwards. Results indicated that ample toilet and rest seats in public spaces ( Living
Environment 5), plenty of exercise space ( Life Function 2), community activities are financially affordable for the elderly ( Community Support 4), A stage with an elderly person's expertise ( Satisfy Needs 3), requiring multiple resource support ( Multiple Resources 4), able to support the elderly entrepreneurship ( Economic Aspects 3), multicultural facilities ( Cultural Characteristics 1) and clear communication of health-care information to the elderly ( Health Care 3) has statistically significant significance, the $F$ verification, $\mathrm{p}<0.05$ ). Among them in the community support and the variable of multiple resources, age is more significant.

\section{Education}

With the education level as the variable, the cognitive importance of elderly people for the construction of healthy community in the various dimensions and variables are based on variables, a single factor variable analysis (One way ANOVA), if significant differences are achieved, then multiple comparisons are performed afterwards. Results showed that there are ample toilets and rest seats in public spaces ( Living Environment 5), friendly high-squatter restaurant ( Life Function 3), community activities are financially affordable for the elderly (Community Support 4), A stage with an elderly person's expertise ( Satisfy Needs 3), 
requiring multiple resource support (Multiple Resources 4), able to support the elderly entrepreneurship (Economic Aspects 3), Cultural activities with Community characteristics ( Cultural Characteristics 3) and have sufficient and perfect medical services ( Health Care 1 is statistically significant, with the $F$ verification , $p<0.05)$. The higher the education level, the more significant the impact.

\section{Working Condition}

Taking work as a variable, the cognitive importance of elderly people to construct a healthy community in the various dimensions and variables are based on variables, a single factor variable analysis (One way ANOVA), if significant differences are achieved, then multiple comparisons are performed afterwards. Analysis results indicated that the community has sufficient lighting ( Living Environment 3), convenient transportation ( Life Function 1), community activities are financially affordable for the elderly ( Community Support 4), a stage with senior people's expertise ( Satisfy Needs 3), human resources to build on the ground ( Multiple Resources 2) , can support the elderly people to start a business ( Economic Aspects 3), respect for individual religious beliefs ( Cultural Characteristics 5) and can clearly convey health care information to the elderly ( Health care 3) is statistically significant, $F$ Verification, $\mathrm{p}<0.05)$. The more the retirees are, the more significant are the retired people.

\section{E. Marital Status}

With marriage as the variable, the cognitive importance of elderly people for the construction of health community in the various dimensions and variables are based on variables, a single factor variable analysis (One way ANOVA), if significant differences are achieved, then multiple comparisons are performed afterwards. Analysis Results indicated that community road leveling ( Living Environment 2), shopping environment for elderly people's needs ( Life Function 4), community activity is affordable for seniors ( Community Support 4), the elderly have the opportunity to contribute to the service (Satisfy Needs 5), human resources to be established on the ground ( Multiple Resources 2), helping the elderly to get re-employment ( Economic Aspect 2), can preserve historical monuments ( Cultural Characteristics 4) and multiple health promotion activities ( Health Care 5) and so statistically significant, F Verification, $\mathrm{p}<0.05)$. The elderly people who were unmarried or divorced were more aware of the cultural and medical facets.

\section{F. Living Status}

With the living condition as the variable, the cognitive importance of elderly people for the construction of health community in the various dimensions and variables are based on variables, a single factor variable analysis (One way ANOVA), if significant differences are achieved, then multiple comparisons are performed afterwards. Analysis Results indicated that community security space ( Living Environment 4), elderly friendly restaurant ( Life Function 3, community activity is affordable for seniors ( Community Support 4), a stage with the most senior person's expertise (Satisfy Needs 3), organized in a mutual aid group ( Multiple Resources 3, providing re-employment opportunities for the elderly ( Economic Aspect 2), respect for individual religious beliefs ( Cultural Characteristics 5) and can clearly communicate health care information to the elderly ( Health Care 3) and so statistically significant, F Verification, $\mathrm{p}<0.05$ ) . The elderly people who live with their spouses have a slightly more cognitive understanding of living environment, community support and multiple resources.

\section{G. Health}

With the health status as the variable, the cognitive importance of elderly people for the construction of health community in the various dimensions and variables are based on variables, a single factor variable analysis (One way ANOVA), if significant differences are achieved, then multiple comparisons are performed afterwards. Analysis Results showed that community with adequate lighting ( Living Environment 3), elderly friendly restaurant ( Life Function 3), enough activity for seniors to participate (Community Support 2 ), older people have the opportunity to contribute to the service (Satisfy Needs 5), requires support for multiple resources ( Multiple Resources 4) providing re-employment opportunities for older people ( Economic Aspects 2) , multicultural facilities ( Cultural Characteristics 1) and multiple health promotion activities ( Health Care 5) and so statistically significant, $F$ Verification, $\mathrm{p}<0.05)$. It is statistically significant that the health condition is very good and the cognition of the elderly is remarkable.

\section{OPEN QUESTIONS}

According to the opening questions, the two aspects of "life function and health care" are still the concerns of the elderly people for the cognitive importance and the needs or demands for constructing the healthy community. The results are similar to those presented in the questions of quantitative studies. However, more worthy of our attention is the recognition and need for "lifelong learning" in the " Satisfy Needs " structure, which includes the provision of more senior technical and recreational training courses for the elderly people, as well as the organization of community sports activities and workshops. This result shows that in addition to the variable of "health", lifelong learning is an important part of the cognitive importance and needs or demands of the healthy community. In other words, the investment of "adult learning and Continuing education" is also one of the key factors in building a healthy community [12]. 
TABLE IV. OPEN ISSUES LIST

\begin{tabular}{ccc}
\hline No. & $\begin{array}{c}\text { Open Item Issues } \\
\text { ( comments and recommendations) }\end{array}$ & Surface description \\
\hline 1 & Accommodation for elderly singletons & Living Environment \\
\hline 2 & An environment with good air & Living Environment \\
\hline 3 & A community setting for older people's sports equipment & Life function \\
\hline 4 & Dining with the elderly at the care point & Life function \\
\hline 5 & In line with school and community activities & Community support \\
\hline 6 & Provide more skills and leisure training courses for elderly people & Satisfy Needs \\
\hline 7 & Organizing more community sports and learning courses & Satisfy Needs \\
\hline 8 & The importance of lifelong learning & Satisfy Needs \\
\hline 9 & Teach the concept of correct life and death and how to deal with it & Health Care \\
\hline 10 & & Health Care \\
\hline
\end{tabular}

\section{CONCLUSION}

The elderly people have the "health care service" as the most important factor to construct the various dimensions and variables of the health community, followed by the "Living Environment", and the "Economic Aspects" and "Multiple Resources" are relatively unimportant. The top 10 of the requirements topics in each configuration are "community sanitation clean"(4.57), "adequate lighting in the community environment"(4.56), "Adequate and perfect medical service" (4.55), "Adequate preventive health care"(4.49), "community provides patrol services to ensure personal security"(4.49), "can clearly convey health care information to the elderly" (4.46) , multiple health promotion activities (4.44), have enough exercise space (4.43), "Helping the disadvantaged" (4.39), "Community safe and accessible public space" (4.36) and good maintenance and management of public facilities (4.36) The last three ones are "able to support the elderly entrepreneurship" (3.31), providing re-employment opportunities for older people (3.45), and "seniors get paid for work" (3.57), all three belong to the "economic aspects" of the construction surface.

The results of the open questionnaire show that in addition to the variable of "health", lifelong learning is an important part of the cognitive importance and needs or demands of the healthy community. In other words, the investment of "adult learning and Continuing education" is also one of the key factors in building a healthy community.

\section{REFERENCES}

[1] Jiang, Chen, Hong, Lin, and Wu (2009). 1999-2007 Age of Successful Aging and Active Aging of Elderly People in Taiwan. Taipei: Health and Welfare Department of National Health. (In Chinese)

[2] He, Lin, Dai, and He (2016). The Influence of the Elderly Community Participation on the Psychological Well-being: Taking the Ping-dong County Community Care Stronghold as an Example. Journal of Community Work and community studies in Taiwan, 6 (3), 45-80. (In Chinese)

[3] Wu and Jain (2010). A Study on the Relationship between Middle-aged Learners ' Leisure Attitude and Active Aging. Adult and lifelong education, (27), 17-28. (In Chinese)

[4] Lu (2012). A Study on Social Integration of the Elderly in Taiwan: Taking Community Life as an Example. Humanities and Social Sciences newsletter, 13(2), 90-96. (In Chinese)

[5] Shen, Tsai, Lian, and Zheng (2015). To Explore the Influence of Different Media on the Image of Tourism Destination. National Education, 55 (3), 37-48. (In Chinese)

[6] Hu (2011). Healthy City Plan: Taking Tainan for an Example. Medical Quality magazine, 5 (5), 25-29. (In Chinese)

[7] Gould (1988). Consumer Attitudes toward Health and Healthcare: a Differential. Journal of Consumer Affairs (1), 96-118. (In Chinese)

[8] Hancock \& Duhl (1986). Promoting Healthy in the Urban Content. Copenhagen: WHO Europe. (In Chinese)

[9] Hsu (2007). Exploring Elderly People's Perspectives on Successful Ageing in Taiwan. Ageing and Society (1), 87-102. (In Chinese)

[10] Miguel Vazquez (2017). Healthy Communities Defined: the Social Determinants of Health. July 14, 2017, Retrieved from https://www.planning.org/blog/blogpost/9124625/. (In Chinese)

[11] WHO (1986). The Ottawa Charter for Health Promotion. November 21, 2016, Retrieved from http://www.who.int/healthpromotion/conferences/previous/ottawa/en/. (In Chinese)

[12] Yates (2007). Active Ageing. Impact, 10. Retrieved from Https://search.informit.com.au/documentSummary/ELHSS. (In Chinese) 